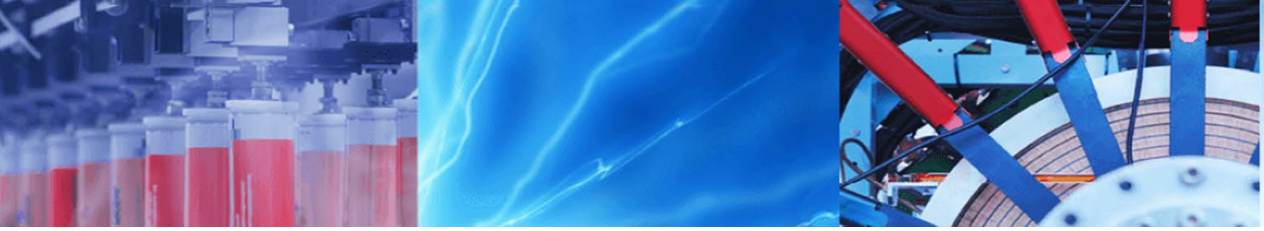

Research Article

\title{
Application of $\mathrm{Y}-\mathrm{ZrO}_{2}$ microtubes as dielectric barrier material in a $\mathrm{He}$ atmospheric pressure micro-plasma jet
}

\author{
Rasmus Talviste $^{1}$ (I) . Indrek Jõgi ${ }^{1} \cdot$ Tanel Tätte $^{1} \cdot$ Marko Part $^{1}$ · Jüri Raud ${ }^{1} \cdot$ Peeter Paris $^{1}$
}

Received: 12 October 2020 / Accepted: 18 December 2020 / Published online: 25 January 2021

(C) The Author(s) 2021 OPEN

\begin{abstract}
This work focused on the application of novel $8 \%$ yttria-stabilized $\mathrm{Zr}_{2} \mathrm{O}_{3}$ (YSZ) microtubes with an inner diameter of $60 \mu \mathrm{m}$ as dielectric material in an atmospheric pressure micro-plasma jet (APPJ). Furthermore, a comparison with quartz microtubes allowed to study the effect of tube material on plasma properties. Optical emission spectroscopy was employed to determine various spectral line ratios including ratios of He lines $667 \mathrm{~nm}\left(3^{1} \mathrm{D}-2^{1} \mathrm{P}\right)$ to $728 \mathrm{~nm}\left(3^{1} \mathrm{~S}-2^{1} \mathrm{P}\right)$ which is indicative of electric field strength. The $667 / 728 \mathrm{~nm}$ line ratio in the YSZ microtube was about $2 / 3$ the value in the $60-\mu \mathrm{m}$ quartz tube. However, increasing the quartz tube's inner diameter from 60 to $500 \mu \mathrm{m}$ decreased the $667 / 728 \mathrm{~nm}$ line ratio 40 times. Additionally, the spatio-temporal evolution of the ionization wave was measured in the YSZ microtube and the velocity of the ionization wave was determined to accelerate from $67 \mathrm{~km} / \mathrm{s}$ near the powered electrode to $161 \mathrm{~km} / \mathrm{s}$ near the tube orifice.
\end{abstract}

Keywords Atmospheric pressure plasma jet · Ionization wave $\cdot$ Micro-plasma $\cdot$ Yttria-stabilized zirconia $\cdot$ Ceramic microtubes

\begin{tabular}{ll}
\multicolumn{2}{l}{ Abbreviations } \\
APPJ & Atmospheric pressure plasma jet \\
ID & Inner diameter \\
N2 SPS-N2 & Second positive system \\
OE & Optical emission \\
PMT & Photomultiplier tube \\
YSZ & $8 \%$ Yttria-stabilized Zr2O3
\end{tabular}

\section{Introduction}

Non-equilibrium atmospheric pressure plasma jets (APPJ) are cold plasma devices which are typically operated by flowing a noble gas through a dielectric capillary and applying an AC voltage to an inner or outer electrode [1]. The primary motivation behind the research of APPJs is the applicability of cold plasmas in biomedicine such as sterilization [2,3], wound healing [4], dental surface treatment [5] and cancer therapy [6, 7]. Potential applications further include localized treatment of temperature-sensitive materials [8], ionization source in miniature mass spectrometers $[9,10]$, plasma photonic crystals (PPCs) [11-13], flow control $[14,15]$ and possibly as thrusters in space technology [16]. Many applications of APPJs rely on the plasma production of active species $[17,18]$ which is dependent on several parameters including the electric field strength [19-21]. While the knowledge of APPJs has advanced considerably [1], the characteristics of APPJs, such as optical emission, electron density, electron temperature and electric field strength, are still actively investigated [22-26].

Typically, in APPJs the tubular dielectric material is quartz, glass or occasionally alumina ceramics which have a dielectric constant in the range of 4-9 [27]. Several computational works have shown that dielectric permittivity of the capillary material affects the properties (e.g. production of active species and electric field strength) of the APPJ $[28,29]$. Experimental investigation of the effect of

Rasmus Talviste, rasmus.talviste@ut.ee | 'Institute of Physics, University of Tartu, W. Ostwaldi tn. 1, 50411 Tartu, Estonia. 
relative permittivity on properties of APPJs and comparison with calculations requires materials with considerably higher relative permittivity values. To our knowledge, no such experimental works exist. However, we recently demonstrated the possibility to ignite a discharge in a single $\mathrm{Y}-\mathrm{ZrO}_{2}$ nanoceramic microtube in $\mathrm{He}$ flow at atmospheric pressure [30].

$\mathrm{Y}-\mathrm{ZrO}_{2}$ or $\mathrm{YSZ}$ is a material, where yttria is required to stabilize zirconia at room temperature in the tetragonal/ cubic phase. YSZ has high dielectric constant (32-42) [31], refractive index $(2.15-2.2)[32,33]$ excellent mechanical properties and fracture toughness, chemical resistance and biocompatibility. Due to those properties, YSZ is a very important engineering material that has found use in various fields ranging from dentistry [34] to metallurgy [35]. High-temperature ionic conductance of YSZ enables the use as electrolyte in solid oxide fuel cells [36]. In our previous works, a method was proposed for the preparation of high-quality YSZ microtubes with a diameter below $100 \mu \mathrm{m}$ and wall thickness less than $20 \mu \mathrm{m}[30,37,38]$. The tubes were composed of structurally homogeneous $100 \%$ cubic phase $8 \%$ yttria-stabilized zirconia. Additionally, these $8 \%$ YSZ microtubes showed properties such as nanoscale structural homogeneity, perfectly round-shape cross-sectional geometry, high surface smoothness and high-density structure and possess optical wave-guiding properties. To the best of our knowledge, there is no alternative method proposed in the literature for the preparation of YSZ nanoceramic microtubes in those dimensions and especially in described quality.

The aim of this work was to characterize a novel microscale APPJ in YSZ microtubes ignited by a $\mathrm{kHz}$ sinusoidal voltage in He gas flow. Optical emission spectra were registered along the axis of the YSZ microtube, and spatio-temporal evolution of the ionization wave in the YSZ microtube was determined. Several line ratios were identified to characterize trends in excited species concentrations and changes in the electric field strength according to several experimental and theoretical works $[39,40]$. The line ratios were compared with measurements in quartz tubes of similar diameters to identify the effect of the tube material. The knowledge of excited species concentrations and spatio-temporal evolution of the discharge in case of APPJ in a YSZ microtube provides initial point of comparison with existing computational works.

\section{Experimental set-up}

The $8 \%$ YSZ microtubes used in the current study were prepared as thoroughly described and characterized in previous publications [30, 37, 38]. The YSZ microtube was melt-jointed onto a top of a large quartz Pasteur pipette capillary (inner diameter ID $=5.5 \mathrm{~mm}$ ) which narrowed down to about $100 \mu \mathrm{m}$ on the one end, similarly as described in [30]. Narrowing as well as melt-jointing was achieved in the flame of heat gun Kemper 12,500 Micro. After melt-jointing, the YSZ microtube was brought into contact with a copper half-circle using micrometre positioning mechanics. Platinum paste MaTeck $\mathrm{C} 3605$ was carefully smeared around the microtube and the rim of copper half-circle. The removal of organic solvents and densification of the paste were achieved with a heat gun. The flame was shifted carefully towards the joint until a transition of black colour of the paste to metallic grey was observed. As a result, temperature-resistant conductive Pt-joint was created. Figure 1a shows the discharge inside a YSZ microtube (length $10-20 \mathrm{~mm}$; ID = $60 \mu \mathrm{m}$; and wall thickness $15 \mu \mathrm{m}$ ).

Experimental set-up used for the investigation of the APPJ inside the YSZ microtube is depicted in Fig. 1b. The set-up is similar to the one in our previous studies used for the characterization of quartz tubes [41-45]. Plasma was ignited by a constant frequency $(6 \mathrm{kHz})$ sinusoidal voltage applied to the platinum electrode. Plasma could be sustained between 8 and $16 \mathrm{kV}$, and the spectral and spatio-temporal characterization was carried out at $12.5 \mathrm{kV}$. Helium (purity of 5.0) flow was controlled by an Alicat Scientific flow controller and fed into the microtube through the larger quartz capillary with the flow rate of $10 \mathrm{sccm}$ (linear velocity of $59 \mathrm{~m} / \mathrm{s}$ ). The Reynolds number was calculated according to $\operatorname{Re}=(\rho \cdot V \cdot D) / \mu^{\prime}$ where $\rho$ and $\mu$ are, respectively, the density and viscosity constant of $\mathrm{He}, V$ is the linear He flow velocity and $D$ is the microtube diameter. This gives a Reynolds number of 31 in the $60-\mu \mathrm{m}$ YSZ microtube which according to Xiong et al. [46] is in the laminar flow regime for APPJs. The set-up was flushed with $\mathrm{He}$ for 2-3 $\mathrm{h}$ prior to experiments, but as can be seen from the spectrum in Fig. 3 emission of $\mathrm{N}_{2}, \mathrm{OH}$ and $\mathrm{O}$ is detectable due to the presence of $\mathrm{N}_{2}, \mathrm{O}_{2}$ and water vapour impurities originating likely from the walls of the gas tubing. In the case of quartz tubes (ID $=60$ and $500 \mu \mathrm{m}$ ), we used a set-up similarly as depicted in Fig. $1 \mathrm{~b}$ and identical as described thoroughly in our previous works $[43,45]$.

A Tektronix TDS-540B oscilloscope was used to record electrical characteristics. The voltage was measured with a voltage probe which consisted of a capacitive voltage divider (1:1270) and 1:10 Tektronix P6139A probe. We assumed that the uncertainty of the oscilloscope measurements was about $1 \%$; however, the magnitude of the short current pulse corresponding to the development of ionization waves varied within $50 \%$. A grounded copper plate electrode was placed $20 \mathrm{~mm}$ downstream from the tube orifice, and a glass sheet (thickness $5 \mathrm{~mm}$ ) was 

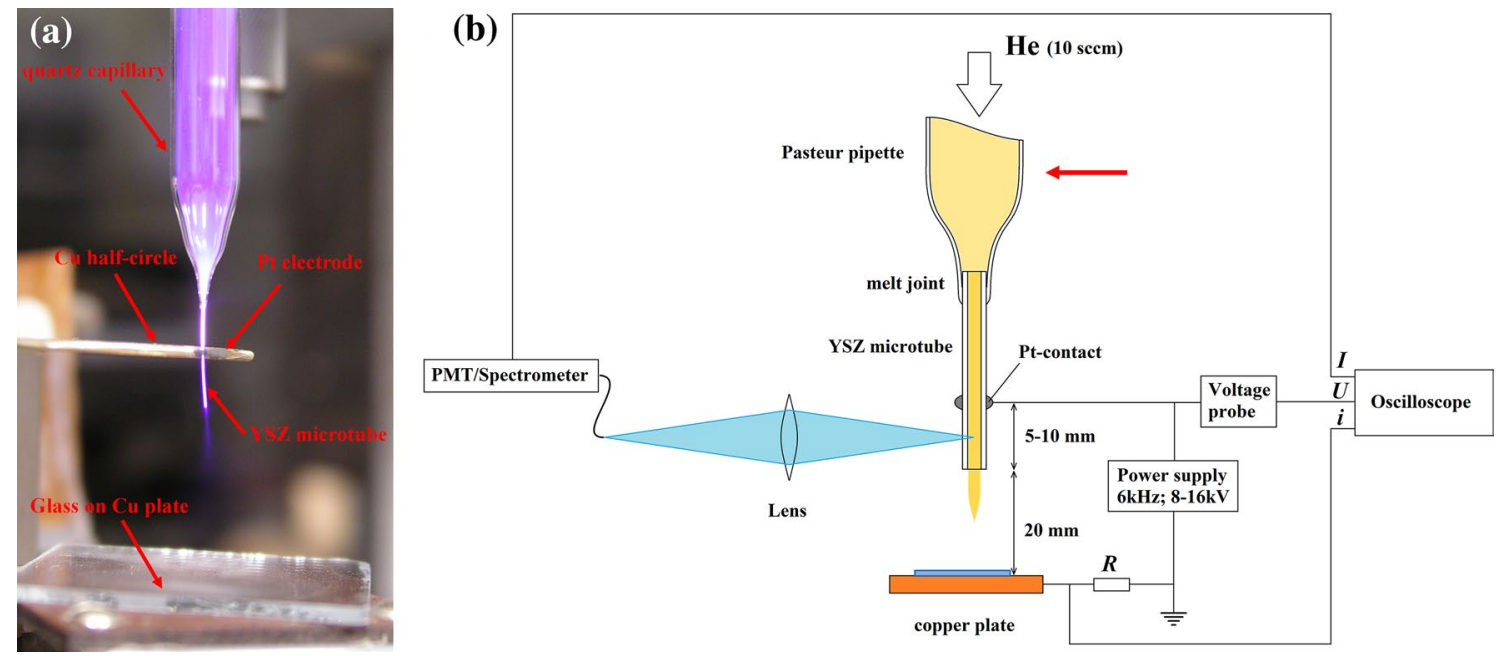

Fig. 1 Image of the APPJ in the $8 \%$ YSZ tube (ID =60 $\mu \mathrm{m})$ operated at $16 \mathrm{kV}$ a and schematic of the experimental set-up b. R-resistor, $\mathrm{i}$-current, $\mathrm{U}$-voltage, and I-emission intensity measured by

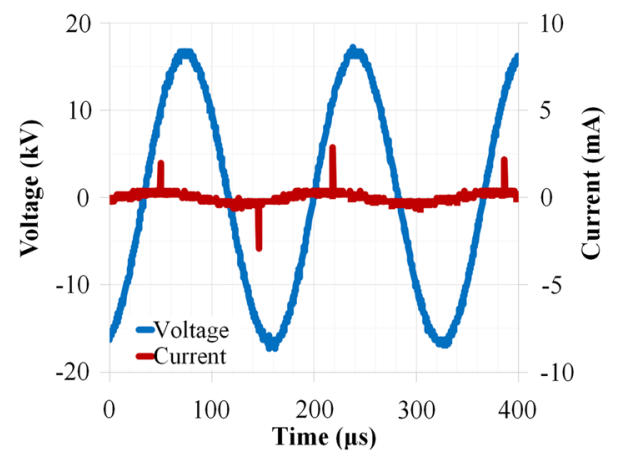

Fig. 2 Voltage and current waveforms of the APPJ in YSZ microtube. The shape and duration of the current pulse are shown in Fig. $6 a$

placed on the copper plate. It was checked visually that the plasma did not reach the grounded electrode and emission intensities in the spectra were not affected by the presence or absence of the grounded electrode [43]. The temporal evolution of the current was determined from the voltage drop at the resistor $(R \approx 1.3 \mathrm{k} \Omega$ ) between the copper plate and ground. An example of the voltage and current waveforms over several half-cycles is shown in Fig. 2. The current waveform consisted of the sinusoidal displacement current and short voltage pulses corresponding to the development of ionization waves. Formation of current pulses had better repeatability during the positive half-cycle. The duration of the current pulses was about 300 ns, and the shape is shown in Fig. 6a.

Optical emission from the plasma was collected with a lens system with a focal length of $60 \mathrm{~mm}$ and projected with a magnification of 1:1 onto an optical fibre of $1 \mathrm{~mm}$ photomultiplier (PMT). Red arrow shown in $\mathbf{b}$ depicts the measurement direction in the large quartz Pasteur pipette (ID $=5.5 \mathrm{~mm}$ )

diameter. The optical fibre was connected to either a Hamamatsu 1P28A photomultiplier tube (PMT) or Ocean Optics 2000 spectrometer with a spectral resolution of $1 \mathrm{~nm}$. The light emission was recorded from the side direction along the axis of the tube by moving the optical fibre in steps of $1 \mathrm{~mm}$ with an uncertainty and spatial resolution of $0.5 \mathrm{~mm}$ for both spectral and spatio-temporal characterization. Spectra were averaged over 10 spectra with the acquisition time of $1 \mathrm{~s}$ for each spectrum. Consequently, the measured line intensities and intensity ratios represent an average value over both positive and negative voltage half-cycles. Relative spectral sensitivity of the spectroscopic systems was determined in energetic units by using a deuterium-halogen calibration source Ocean Optics DH-2000-CAL. The spectra acquired at the same axial position were reproducible within the margin of $10 \%$. Comparison spectra of an APPJ in quartz capillaries (ID $=60$ and $500 \mu \mathrm{m}$ ) were obtained with the exact set-up as thoroughly described in our previous works $[43,45]$ at a flow rate of 20 and $100 \mathrm{sccm}$ and applied voltage amplitude of $13.6 \mathrm{kV}$ and $12.5 \mathrm{kV}$, respectively. In all cases, the flow was maintained in the laminar flow regime [46]. The average linear velocity, calculated by dividing the volume flow by cross-sectional area, was $59 \mathrm{~m} / \mathrm{s}$ in the YSZ microtube and 8.5 and $118 \mathrm{~m} / \mathrm{s}$ in the $500-$ and $60-\mu \mathrm{m}$ quartz tubes, respectively.

The development of ionization waves was determined by recording the current and optical emission with the PMT during a single current pulse. The spectral response of the PMT used in this work is optimal between 200 and $520 \mathrm{~nm}$ declining exponentially at higher wavelengths. Recording of current and corresponding optical emission was triggered from current with set levels for current 
amplitude (2-3 mA) to separate the first pulse of each half-cycle as was done in our previous work $[43,45]$. The current pulses had to be used for the triggering because the ionization waves started at random times in respect to the sinusoidal voltage waveform. The jitter between the onset of current pulse and the optical emission pulse at a certain point along the jet axis remained below $10 \mathrm{~ns}$. In the measurements, the resolution of the oscilloscope was $100 \mathrm{~ns} /$ div ( $2 \mathrm{~ns}$ per data point) which was taken as the uncertainty. The propagation velocity of the ionization wave was calculated from the time delay between the onsets of current pulse and optical emission pulse in different positions along the tube axis similarly as in our previous work [43-45]. Time delay (10 ns) caused by different lengths of cables used for electrical and PMT signal transmission to oscilloscope was accounted for.

\section{Results and discussion}

\subsection{A. Spectral characterization}

Figure 3 depicts the normalized optical emission intensity registered in the $60-\mu \mathrm{m}$ YSZ microtube $4 \mathrm{~mm}$ downstream from the powered electrode and in the large quartz tube $(I D=5.5 \mathrm{~mm}$; at the position of the red arrow in Fig. 1b) $7 \mathrm{~mm}$ upstream from the powered electrode at a He flow rate of $10 \mathrm{sccm}$ and applied voltage of $12.5 \mathrm{kV}$. The spectra acquired at the same axial position were reproducible within the margin of $10 \%$. Both spectra were normalized to the intensity of the bandhead of the $0-0$ transition of $\mathrm{N}_{2}$ at $337 \mathrm{~nm}$ which was seven times more intense in the YSZ microtube.

Inside the YSZ microtube, the strongest emission belongs to $N_{2}$ second positive system (SPS; $C^{3} \Pi_{u}-B^{2} \Pi_{g}$ ) transitions with bandheads at $337 \mathrm{~nm}\left(C^{3} \Pi_{\mathrm{u}}-\mathrm{B}^{2} \Pi_{\mathrm{g}^{\prime}} 0-0\right)$ and $357 \mathrm{~nm}\left(C^{3} \Pi_{u}-B^{2} \Pi_{q^{\prime}} 0-1\right)$ and He lines at $587 \mathrm{~nm}$ $\left(3^{3} \mathrm{D}-2^{3} \mathrm{P}\right)$ and $667 \mathrm{~nm}\left(3^{1} \mathrm{D}-2^{1} \mathrm{P}\right)$. This agrees well with the yellowish purple colour of the plasma inside the microtube as shown in Fig. 1a. Other notable emissions stem from $\mathrm{He}$ lines $706 \mathrm{~nm}\left(3^{3} \mathrm{~S}-2^{3} \mathrm{P}\right)$ and $728 \mathrm{~nm}\left(3^{1} \mathrm{~S}-2^{1} \mathrm{P}\right)$, the $\mathrm{N}_{2}{ }^{+}$first negative system (FNS) bandhead at $391 \mathrm{~nm}\left(\mathrm{~B}_{2} \Sigma_{0}{ }^{+}-\mathrm{X}_{2} \Sigma_{0}{ }^{+}\right)$ and the $\mathrm{OH}\left(\mathrm{A}^{2} \Sigma^{+}-\mathrm{X}^{2} \Pi, 0-0\right)$ band at $308 \mathrm{~nm}$. Atomic $\mathrm{O}$ triplet is also visible at $777 \mathrm{~nm}\left({ }^{5} \mathrm{P}-{ }^{5} \mathrm{~S}^{0}\right)$. Albeit relatively less intensive, the $\mathrm{H}_{\alpha}(656 \mathrm{~nm})$ and $\mathrm{H}_{\beta}(486 \mathrm{~nm})$ lines of the hydrogen Balmer series are also detectable. The major spectral difference in the large quartz tube attached to the YSZ microtube was the much less intense He lines, and only the $706 \mathrm{~nm}$ line has comparable intensity in these spectra. In the larger quartz tube, the $391 \mathrm{~nm}$ line and the $777 \mathrm{~nm} O$ triplets are relatively more intense than in the YSZ microtube.
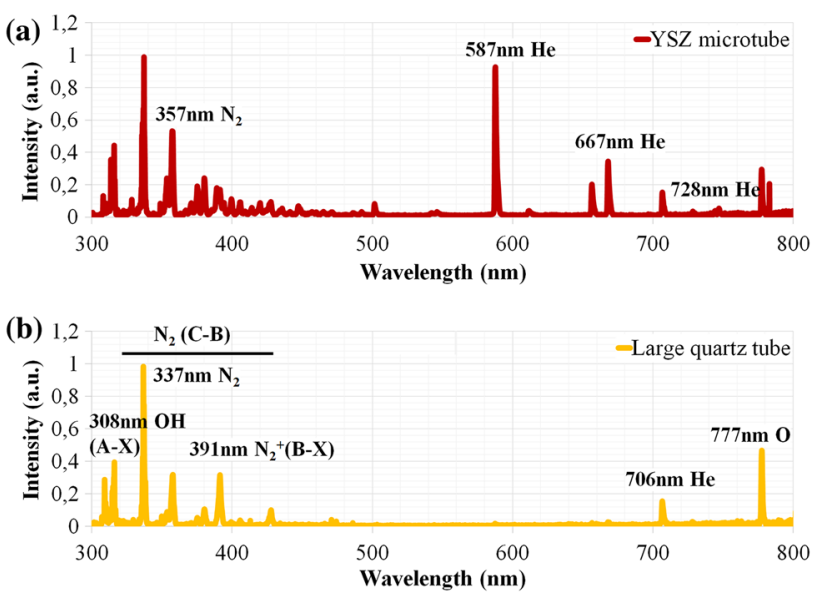

Fig. 3 Normalized spectra registered inside the YSZ microtube $(I D=60 \mu \mathrm{m}) 4 \mathrm{~mm}$ downstream from the powered electrode a and in the larger quartz tube (ID $5.5 \mathrm{~mm}$ ) $7 \mathrm{~mm}$ upstream from the powered electrode $\mathbf{b}$. Note that the spectrum in the larger quartz tube is offset by 1

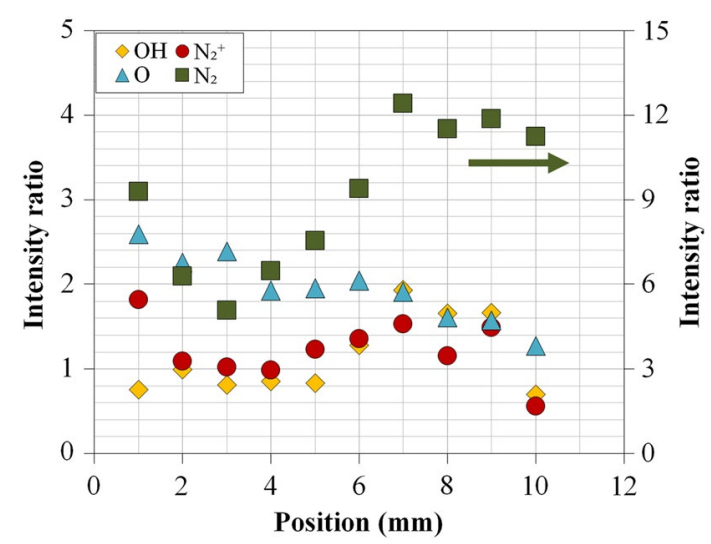

Fig. 4 Spatial evolution of various line intensity ratios to the $706 \mathrm{~nm}$ He line along the axis of a YSZ microtube $(I D=60 \mu \mathrm{m})$ downstream from the electrode at position 0 . Position $10 \mathrm{~mm}$ marks the tube orifice. Note the different scale for the 337/706 $\left(\mathrm{N}_{2}\right)$ $\mathrm{nm}$ line ratio

The spectra shown in Fig. 3 highlight the change of colour from purplish in the large quartz tube to yellowish in the YSZ microtube as shown in Fig. 1a. The purple colour in the large quartz tube is caused by the predominance of emission from $\mathrm{N}_{2}$ SPS, while the dominant He line at $587 \mathrm{~nm}$ is responsible for the yellow emission in the YSZ microtube. The following figures present spectral line ratios of the most important radiating species present in the plasma.

Figure 4 shows the spatial evolution of line ratios of $\mathrm{OH}(308 \mathrm{~nm}), \mathrm{N}_{2}(337 \mathrm{~nm}), \mathrm{N}_{2}{ }^{+}(391 \mathrm{~nm})$ and the atomic O triplet at $777 \mathrm{~nm}$ to the $\mathrm{He} 706 \mathrm{~nm}$ line along the YSZ microtube axis downstream from the powered electrode. 
Both the $337 / 706$ and the $357 / 706 \mathrm{~nm}$ line ratios showed similar trends and were several times higher than the line ratios of $\mathrm{OH}, \mathrm{O}$ and $\mathrm{N}_{2}^{+}$. Starting from the electrode, the ratios of $337 / 706$ and $357 / 706 \mathrm{~nm}$ decreased, and a minimum was observed $3 \mathrm{~mm}$ downstream from the electrode. Further downstream the ratios increased up to $8 \mathrm{~mm}$ and then were constant up to the tube orifice. The line ratios of the 308/706 and 391/706 $\mathrm{nm}$ were lower and behaved similarly as the $\mathrm{N}_{2}$ SPS $\left(\mathrm{C}^{3} \Pi_{\mathrm{u}}-\mathrm{B}^{2} \Pi_{\mathrm{g}}\right)$ transitions; however, the changes were less pronounced and further downstream from $8 \mathrm{~mm}$ the ratios decreased. The ratio of atomic O triplet at 777/706 $\mathrm{nm}$ showed a maximum below the electrode and then slightly decreased towards the tube orifice. The intensity of a spectral transition is proportional to the density of radiating species in the excited radiating state which in turn depends on plasma parameters such as electron density and temperature [47]. Using line ratios over line/band intensities has the advantage that in case of direct electron impact excitation from the ground state, the dependence on electron density vanishes. At such conditions, the intensity ratio is determined only by the densities of neutrals and electron temperature.

Figure 5 shows the spatial evolution of $\mathrm{He} 667 \mathrm{~nm}$ $\left(3^{1} \mathrm{D}-2^{1} \mathrm{P}\right)$ to the $728 \mathrm{~nm}\left(3^{1} \mathrm{~S}-2^{1} \mathrm{P}\right)$ line ratio inside the YSZ microtube. The 587/706 nm line ratio (not shown) in the YSZ microtube was slightly higher varying from 4 to 7 and showed similar tendencies as the $667 / 728 \mathrm{~nm}$ ratio. The spectra inside the YSZ microtube and the large quartz tube used to feed the He gas to YSZ microtube were considerably different (Fig. 3). Therefore, to provide comparison on the effect of microtube material and diameter, the line ratios in the 60 - and $500-\mu \mathrm{m}$ quartz tube are presented in Figure 5. In the YSZ microtube, both the 667/728 and 587/706 $\mathrm{nm}$ line ratios had an average value of 5.1

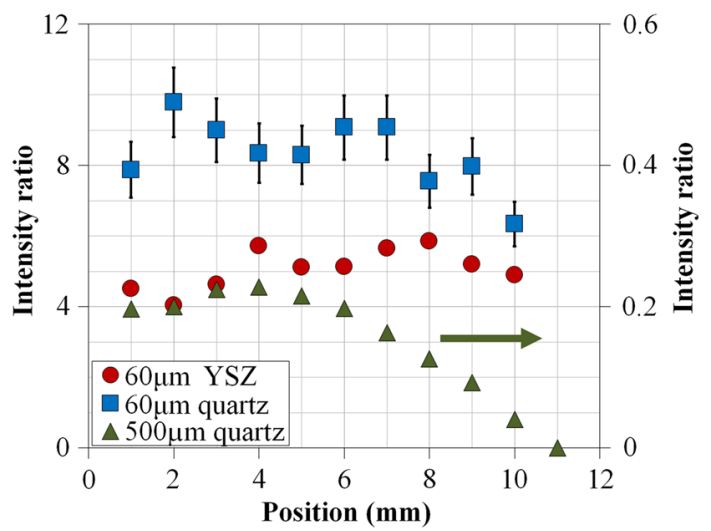

Fig. 5 Spatial evolution of the $667 / 728 \mathrm{~nm}$ line intensity ratio along the axis of YSZ microtube $(I D=60 \mu \mathrm{m})$ and comparison with a quartz tube (ID $=60 \mu \mathrm{m}$ and $500 \mu \mathrm{m})$ downstream from the electrode at position 0 . Position $10 \mathrm{~mm}$ marks the tube orifice. Note the different scale for the line ratio in the $500-\mu \mathrm{m}$ quartz tube and 6 , respectively, and can be taken as constant along the axis since the variation remained less than 2.5 times of the average value. In the $60-\mu \mathrm{m}$ quartz capillary, the $667 / 728 \mathrm{~nm}$ ratio was higher than in the YSZ microtube and had an average value of 8.3 up to position $8 \mathrm{~mm}$ and then reduced to 6 at the tube orifice. The $667 / 728 \mathrm{~nm}$ line ratio in the $500-\mu \mathrm{m}$ quartz tube is shown on the secondary axis of Fig. 5. The ratio was 0.2 near the powered electrode, started to decline downstream onwards from position 4-5 $\mathrm{mm}$ and reached nearly 0 at the tube orifice.

Both He line ratios (587/706 nm and $667 / 728 \mathrm{~nm}$ ) have been used as an indicator for the electric field strength $[39,40]$. Furthermore, Ivkovic et al. developed a collisional radiative model for the calculation of the $667 / 728 \mathrm{~nm}$ line ratio as a function of electric field strength and for electric field strength in the range of $3-40 \mathrm{kV} / \mathrm{cm}$ [40]. They further validated the model by using Stark polarization spectroscopy in a dielectric barrier discharge. The analytical formula proposed in that work has the form $\mathrm{E}\left(\mathrm{kV} / \mathrm{cm}^{-1}\right)=2.2$ $24-20.18 \cdot R+45.07 \cdot R^{2}-19.98 \cdot R^{3}+3.369 \cdot R^{4}[40]$, where $R$ is the $667 / 728 \mathrm{~nm}$ line intensity ratio. In our case, the use of this formula results in electrical field values of several hundred $\mathrm{kV} / \mathrm{cm}$ which is outside the electric field range which was used to obtain the analytical formula. Therefore, we cannot expect that the formula gives quantitatively correct values for the electric field and only the line ratios are shown in the present study. Nevertheless, practically linear dependence between line ratio and electric field strength in the range of $3-40 \mathrm{kV} / \mathrm{cm}$ suggests that the ratio remains a monotonic function of electric field also at our conditions and can be used to assess the electric field variation along the axis of the microtube.

The axial distribution of $667 / 728 \mathrm{~nm}$ line ratio was nearly constant along the whole tube length of 1-10 $\mathrm{mm}$ in 60- $\mu \mathrm{m} \mathrm{YSZ}$ and quartz tubes, while in case of the 500$\mu \mathrm{m}$ quartz tube the ratio started to decrease at the distance of $6 \mathrm{~mm}$ and reduced to 0 near the tube orifice. This result does not suggest that the electric field reduced to 0 near the orifice. In fact, the electric field in the $500-\mu \mathrm{m}$ quartz tube should be of the order of a few to tens $\mathrm{kV} / \mathrm{cm}$ and has been calculated to increase near the tube orifice [48]. In the $500-\mu \mathrm{m}$ quartz tube, the average linear gas velocity was $8.5 \mathrm{~m} / \mathrm{s}$ which was about seven times lower than in the YSZ microtube and about 14 times lower than in the $60-\mu \mathrm{m}$ quartz tube. This can affect the gas purity near the tube orifice as a result of back-diffusion of air impurities. Air impurities create additional loss channels for $3^{1} D$ and $3^{1} S$ excited states of He which were not taken into account in the model by Ivkovic et al. and were used for $\mathrm{E} / \mathrm{N}$ determination from the $\mathrm{He} 667 / 728$ line ratio [40]. Nonetheless, between positions 1 and $6 \mathrm{~mm}$ the $667 / 728 \mathrm{~nm}$ line ratio remained constant, and the effect of impurities is expectedly negligible. Therefore, we expect 
that in the $500-\mu \mathrm{m}$ quartz tube between positions 1 and $6 \mathrm{~mm}$ is the $667 / 728 \mathrm{~nm}$ line ratio indicative of the electric field strength. For smaller tubes, the line ratio can be used for the estimation of electric field strength for the whole length of the tube.

The reduction in $667 / 728 \mathrm{~nm}$ line ratio by about 40 times when increasing the quartz tube diameter from 60 to $500 \mu \mathrm{m}$ indicates that the electric field was greatly enhanced in tubes with smaller diameter. The $667 / 728 \mathrm{~nm}$ line ratio was also about 2/3 lower in the YSZ microtubes than in $60-\mu \mathrm{m}$ quartz capillary which shows that the effect of the capillary material was smaller than the effect of diameter. Additionally, the $667 / 728 \mathrm{~nm}$ line ratio was checked for a $100-\mu \mathrm{m}$ quartz tube $3 \mathrm{~mm}$ below the electrode with the same experimental configuration and was found to be 6.8 which is less than in the $60-\mu \mathrm{m}$ quartz tube but still higher than in the YSZ microtube.

The comparison of $667 / 728 \mathrm{~nm}$ line ratio for YSZ microtubes demonstrated that the average electric field strength in the YSZ microtube is lower than in a quartz tube of comparable diameter. Jansky et al. [28] calculated the electric field distribution in a dielectric tube as a function of tube permittivity and found that the field actually increased near the surface and decreased on the axis of the tube with increasing relative permittivity. In this work, decreased $667 / 728 \mathrm{~nm}$ line ratio in case of YSZ microtubes suggests that the decreased field near the tube axis determines the excitation of $3^{1} D$ and $3^{1} S$ states of $\mathrm{He}$ and the intensity of the 667 and $728 \mathrm{~nm}$ lines. The high-field region near the tube inner surface as calculated by Jansky et al. appears to be less important in the present APPJ configuration. It should be noted that according to the calculations of Jansky et al. the effect of relative permittivity is also dependent on the tube radius and the differences in the electric fields may vary for other tube radii.

\subsection{B. Spatio-temporal development of the ionization wave}

Figure 6a shows an example of a typical current pulse during the positive half-cycle of applied voltage together with integral optical emission collected with the PMT at different positions along the YSZ microtube axis downstream from the powered electrode. Figure $6 \mathrm{~b}$ shows the integrated emission intensity registered with the PMT as a function of position at 80 and $120 \mathrm{~ns}$. The sharp increase in optical emission at a certain time or distance corresponds to the ionization wave reaching that position. The current reached a maximum of 3.5-4 $\mathrm{mA}$ after about $100 \mathrm{~ns}$ from the onset of the current pulse and then decayed slowly. A change in the shape of optical emission occurred at about 90 ns near the current maximum and coincided with the maximum of optical emission at position $7 \mathrm{~mm}$. Before
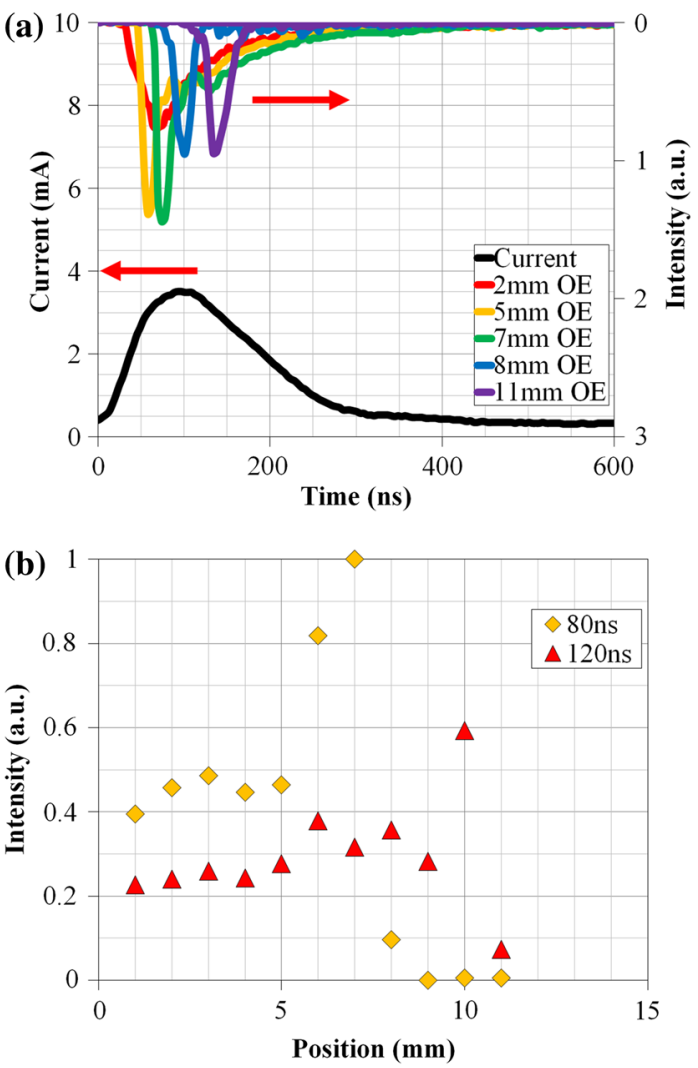

Fig. 6 Temporal evolution of optical emission corresponding to the luminous front together with the recorded current (black) during the positive half-cycle in the YSZ microtube downstream from the powered electrode at position 0 a. Optical emission intensity is shown by red $2 \mathrm{~mm}$; yellow $5 \mathrm{~mm}$; green $7 \mathrm{~mm}$; blue $8 \mathrm{~mm}$; and purple $11 \mathrm{~mm}$. Integrated emission intensity as registered with the PMT as a function of position from the powered electrode at 80 and $120 \mathrm{~ns}$ b. Position $10 \mathrm{~mm}$ marks the tube orifice

this time, i.e. positions up to $7 \mathrm{~mm}$, the optical emission decayed slowly in about 300 ns similarly to the current pulse decay. Further downstream from $7 \mathrm{~mm}$ the emission diminished faster and lasted only about $70-80 \mathrm{~ns}$. A possible explanation to this effect could be the excitation of $\mathrm{N}_{2}\left(C^{3} \Pi_{\mathrm{u}}\right)$ states from the He metastable states $2^{1} \mathrm{~S}$ and $2^{3} \mathrm{~S}$ in the microtube. This would prolong the $\mathrm{N}_{2}$ SPS emission and result in longer optical emission profiles (up to position 7). Closer to the tube orifice, the increasing concentration of air impurities starts to quench the He metastable states more quickly and the emission diminishes faster.

Figure 7 shows temporal evolution of the ionization wave front as determined from the time delay difference between the current and optical emission onset. Optical emission could be registered $1 \mathrm{~mm}$ downstream from the tube orifice, and the ionization wave did not propagate any further in the ambient air. The time it took for the ionization to propagate $11 \mathrm{~mm}$ was $100 \mathrm{~ns}$. Figure 7 shows linear fits which yield an initial ionization wave 


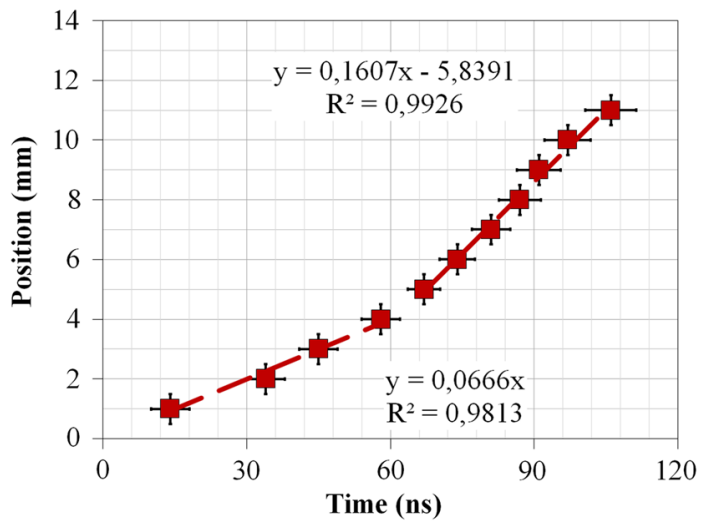

Fig. 7 Temporal evolution of the ionization wave during the positive half-cycle in a YSZ microtube $(I D=60 \mu \mathrm{m})$ downstream from the electrode at position 0 . Position $10 \mathrm{~mm}$ marks the tube orifice

propagation velocity of $67 \mathrm{~km} / \mathrm{s}$ (positions 1-4 mm) which accelerated further downstream $(4-11 \mathrm{~mm})$ to a propagation velocity of $161 \mathrm{~km} / \mathrm{s}$. The velocity of the ionization wave measured along the YSZ microtube is comparable with our previous results in quartz microcapillaries [45].

The initial velocity of $67 \mathrm{~km} / \mathrm{s}$ is the same as measured in our previous work in an $80-\mu \mathrm{m}$ quartz capillary with a similar set-up. The velocity of $161 \mathrm{~km} / \mathrm{s}$ near the YSZ tube orifice is also practically the same as the $170 \mathrm{~km} / \mathrm{s}$ measured in an $80-\mu \mathrm{m}$ quartz tube. This result is in disagreement with the clearly lower electric field strength obtained in YSZ microtube according to line ratio measurements (Fig. 4), and the previous work by Ivković et al. demonstrated positive correlation between ionization wave velocity and electric field strength [40]. Therefore, lower $667 / 728 \mathrm{~nm}$ line ratio in YSZ microtubes (Fig. 5) indicates that the ionization wave velocity should expectedly be lower in the YSZ microtube as compared to quartz tubes with similar inner diameter as studied in our previous work [45]. In that same study, ionization wave velocity increased with decreasing quartz tube diameter [45] which is in accordance with the reduced $667 / 728 \mathrm{~nm}$ line ratio in 500- $\mu \mathrm{m}$ compared to $60-\mu \mathrm{m}$ quartz tubes. However, it should be noted though that the dependence between electric field and velocity is not unique and seems to depend on the plasma jet configuration $[49,50]$. In this work, the electrode preparation for YSZ microtubes was not completely identical to APPJ in quartz capillaries as in our previous work and this is likely reason why the velocity was identical in YSZ microtubes as measured in this work and quartz microtubes as measured in our previous work [45], which may have influenced the velocities of the ionization wave.

\section{Summary and conclusions}

Novel nanoceramic YSZ microtubes were applied as dielectric barrier material in a $\mathrm{kHz}$ frequency micro-APPJ in He gas flow. Line ratios indicative of $\mathrm{OH}, \mathrm{N}_{2}, \mathrm{~N}_{2}{ }^{+}$and atomic oxygen excited species were determined from optical emission spectra along the length of the microtube. The line ratios of $667 \mathrm{~nm}$ (He transition $3^{1} \mathrm{D}-2^{1} \mathrm{P}$ ) to $728 \mathrm{~nm}$ (He transition $3^{1} \mathrm{~S}-2^{1} \mathrm{P}$ ) and $587 \mathrm{~nm}$ (He transition $3^{3} \mathrm{D}-2^{3} \mathrm{P}$ ) to $706 \mathrm{~nm}$ (He transition $3^{3} \mathrm{~S}-2^{3} \mathrm{P}$ ) were determined to reflect changes in the electric field. According to the $667 / 728 \mathrm{~nm}$ line ratio, the electric field was smaller in $60-\mu \mathrm{m}$ YSZ microtube compared to the field in the $60-\mu \mathrm{m}$ quartz tube. The effect of tube diameter was more pronounced compared to the tube material. The velocity of the ionization wave in the YSZ microtube was measured to be $67 \mathrm{~km} / \mathrm{s}$ during the first $5 \mathrm{~mm}$ inside the tube and accelerated to $161 \mathrm{~km} / \mathrm{s}$ near the tube orifice which is comparable to the values determined in similar quartz tubes. Quantitative description of the effect of microtube material (i.e. dielectric constant) on electric field, ionization wave development and plasma parameters (electron density and temperature) requires further studies where other APPJ device parameters are identical for YSZ and quartz microtubes.

Acknowledgements This work was supported by Estonian Research Council projects PUT1432 and PSG448.

Data availability The data that support the findings of this study are available from the corresponding author upon reasonable request.

\section{Compliance with Ethical Standards}

Conflict of interest The author declare there is no conflict of interest.

Open Access This article is licensed under a Creative Commons Attribution 4.0 International License, which permits use, sharing, adaptation, distribution and reproduction in any medium or format, as long as you give appropriate credit to the original author(s) and the source, provide a link to the Creative Commons licence, and indicate if changes were made. The images or other third party material in this article are included in the article's Creative Commons licence, unless indicated otherwise in a credit line to the material. If material is not included in the article's Creative Commons licence and your intended use is not permitted by statutory regulation or exceeds the permitted use, you will need to obtain permission directly from the copyright holder. To view a copy of this licence, visit http://creativecommons .org/licenses/by/4.0/.

\section{References}

1. Lu X, Naidis GV, Laroussi M, Ostrikov K (2014) Guided ionization waves: theory and experiments. Phys Rep 540:123-166. https:// doi.org/10.1016/j.physrep.2014.02.006 
2. Kuwahara T, Kuroki T, Yoshida K et al (2012) Development of sterilization device using air nonthermal plasma jet induced by atmospheric pressure corona discharge. Thin Solid Films 523:2-5. https://doi.org/10.1016/j.tsf.2012.05.064

3. Al-rawaf AF, Fuliful FK, Khalaf MK, Oudah HK (2018) Studying the non-thermal plasma jet characteristics and application on bacterial decontamination. J Theor Appl Phys 12:45-51. https:// doi.org/10.1007/s40094-018-0279-y

4. Schmidt A, Bekeschus S, Wende $K$ et al (2017) A cold plasma jet accelerates wound healing in a murine model of fullthickness skin wounds. Exp Dermatol 26:156-162. https://doi. org/10.1111/exd.13156

5. Šantak V, Vesel A, Zaplotnik R et al (2017) Surface treatment of human hard dental tissues with atmospheric pressure plasma jet. Plasma Chem Plasma Process 37:401-413. https://doi. org/10.1007/s11090-016-9777-3

6. Hirst AM, Frame FM, Arya M et al (2016) Low temperature plasmas as emerging cancer therapeutics: the state of play and thoughts for the future. Tumor Biol 37:7021-7031. https://doi. org/10.1007/s13277-016-4911-7

7. Yan D, Sherman JH, Keidar M (2017) Cold atmospheric plasma, a novel promising anti-cancer treatment modality. Oncotarget 8:15977-15995. https://doi.org/10.18632/oncotarget.13304

8. Penkov OV, Khadem M, Lim WS, Kim DE (2015) A review of recent applications of atmospheric pressure plasma jets for materials processing. J Coatings Technol Res 12:225-235. https://doi. org/10.1007/s11998-014-9638-z

9. Olenici-Craciunescu SB, Michels A, Meyer C et al (2009) Characterization of a capillary dielectric barrier plasma jet for use as a soft ionization source by optical emission and ion mobility spectrometry. Spectrochim Acta-Part B At Spectrosc 64:1253-1258. https://doi.org/10.1016/j.sab.2009.10.001

10. Meyer C, Müller S, Gurevich EL, Franzke J (2011) Dielectric barrier discharges in analytical chemistry. Analyst 136:2427-2440. https ://doi.org/10.1039/c0an00994f

11. Sakai O, Sakaguchi T, Tachibana K (2005) Verification of a plasma photonic crystal for microwaves of millimeter wavelength range using two-dimensional array of columnar microplasmas. Appl Phys Lett 87:87-89. https://doi.org/10.1063/1.2147709

12. Yang HJ, Park S, Eden JG (2017) Narrowband attenuation at 157 GHz by a plasma photonic crystal. J Phys D Appl Phys 50:1-5. https://doi.org/10.1088/1361-6463/aa8d5c

13. Wang B, Cappelli MA, Wang B, Cappelli MA (2016) A plasma photonic crystal bandgap device. Appl Phys Lett 108:1-4. https:// doi.org/10.1063/1.4946805

14. Pescini E, Martínez DS, De Giorgi MG, Ficarella A (2018) Characterization of the effects of a dielectric barrier discharge plasma actuator on a coaxial jet in a Bunsen burner. Exp Therm Fluid Sci 91:292-305. https://doi.org/10.1016/j.expthermfl usci.2017.10.009

15. De Giorgi MG, Ficarella A, Sciolti A et al (2017) Improvement of lean flame stability of inverse methane/air diffusion flame by using coaxial dielectric plasma discharge actuators. Energy 126:689-706. https://doi.org/10.1016/j.energy.2017.03.048

16. Charles C, Boswell RW (2012) Measurement and modelling of a radiofrequency micro-thruster. Plasma Sources Sci Technol 21:022002. https://doi.org/10.1088/0963-0252/21/2/022002

17. Lu X, Naidis GV, Laroussi M et al (2016) Reactive species in nonequilibrium atmospheric-pressure plasmas: generation, transport, and biological effects. Phys Rep 630:1-84. https://doi. org/10.1016/j.physrep.2016.03.003

18. Gavahian M, Chu YH, Mousavi Khaneghah A et al (2018) A critical analysis of the cold plasma induced lipid oxidation in foods. Trends Food Sci Technol 77:32-41. https://doi.org/10.1016/j. tifs.2018.04.009
19. Kelly S, Turner MM (2014) Generation of reactive species by an atmospheric pressure plasma jet. Plasma Sources Sci Technol 23:065013. https://doi.org/10.1088/0963-0252/23/6/065013

20. Naidis GV (2014) Production of active species in cold helium-air plasma jets. Plasma Sources Sci Technol 23:065014. https://doi. org/10.1088/0963-0252/23/6/065014

21. Babaeva NY, Kushner MJ (2013) Reactive fluxes delivered by dielectric barrier discharge filaments to slightly wounded skin. J Phys D Appl Phys 46:025401. https://doi.org/10.1088/00223727/46/2/025401

22. Deepak GD, Joshi NK, Prakash R (2018) Model analysis and electrical characterization of atmospheric pressure cold plasma jet in pin electrode configuration. AIP Adv 8:055321. https://doi. org/10.1063/1.5023072

23. Pinchuk ME, Stepanova OM, Astafiev AM et al (2019) Stepwise propagation of a guided streamer along a DBD helium plasma jet fed by biased oscillating voltage. Appl Phys Lett 114:194103. https://doi.org/10.1063/1.5099968

24. Pinchuk ME, Stepanova OM, Gromov M et al (2020) Variation in guided streamer propagation along a DBD plasma jet by tailoring the applied voltage waveform. Appl Phys Lett 116:1-6. https ://doi.org/10.1063/5.0006178

25. Lee W, Tran TN, Oh CH (2020) Study on helium atmospheric pressure plasma jet using collisional-radiative model. Phys Plasmas 27:073502. https://doi.org/10.1063/5.0009768

26. Sharma NK, Misra S, Varun PUN (2020) Experimental and simulation analysis of dielectric barrier discharge based pulsed cold atmospheric pressure plasma jet. Phys Plasmas 27:113502. https ://doi.org/10.1063/5.0018901

27. Bottom VE (1972) Dielectric constants of quartz. J Appl Phys 43:1493-1495. https://doi.org/10.1063/1.1661347

28. Jánský J, Tholin F, Bonaventura Z, Bourdon A (2010) Simulation of the discharge propagation in a capillary tube in air at atmospheric pressure. J Phys D Appl Phys 43:1-13. https://doi. org/10.1088/0022-3727/43/39/395201

29. Jánský J, Bourdon A (2011) Surface charge deposition inside a capillary glass tube by an atmospheric pressure discharge in air. EPJ Appl Phys 55:1-8. https://doi.org/10.1051/epjap/20111 00504

30. Tätte T, Part M, Talviste R et al (2014) Yttria stabilized zirconia microtubes for microfluidics under extreme conditions. RSC Adv 4:17413-17419. https://doi.org/10.1039/c4ra00621f

31. Thompson DP, Dickins AM, Thorp JS (1992) The dielectric properties of zirconia. J Mater Sci 27:2267-2271. https://doi. org/10.1007/BF01117947

32. Wood DL, Nassau K (1982) Refractive index of cubic zirconia stabilized with yttria. Appl Opt 21:2978. https://doi.org/10.1364/ ao.21.002978

33. Wood DL, Nassau K, Kometani TY (1990) Refractive index of Y2O3 stabilized cubic zirconia: variation with composition and wavelength. Appl Opt 29:2485-2488

34. Özkurt Z, Kazazoğlu E (2011) Zirconia dental implants: a literature review. J Oral Implantol 37:367-376. https://doi. org/10.1563/AAID-JOI-D-09-00079

35. Hemberger Y, Berthold C, Nickel KG (2012) Wetting and corrosion of yttria stabilized zirconia by molten slags. J Eur Ceram Soc 32:2859-2866. https://doi.org/10.1016/j.jeurcerams oc.2011.12.005

36. Kendall K, Minh NQ, Singhal SC (2003) Cell and stack design, Chap. 8. In: Singhal SC, Kendall K (eds) High temperature solid oxide fuel cells: fundamentals, design and applications. pp 197-228

37. Hanschmidt K, Tätte T, Hussainova I et al (2013) Optimization of mechanical strength of titania fibers fabricated by direct 
drawing. Appl Phys A Mater Sci Process 113:663-671. https:// doi.org/10.1007/s00339-013-7601-y

38. Part M, Hanschmidt K, Jõgi J et al (2014) Study of the curing mechanism of metal alkoxide liquid threads for the synthesis of metal oxide fibers or microtubes. RSC Adv 4:12545-12554. https://doi.org/10.1039/c3ra47924b

39. Jarrige J, Laroussi M, Karakas E (2010) Formation and dynamics of plasma bullets in a non-thermal plasma jet: influence of the high-voltage parameters on the plume characteristics. Plasma Sources Sci Technol 19:065005. https://doi.org/10.1088/09630252/19/6/065005

40. Ivković S, Sretenović GB, Obradović BM et al (2014) On the use of the intensity ratio of He lines for electric field measurements in atmospheric pressure dielectric barrier discharge. J Phys D Appl Phys 47:055204. https://doi.org/10.1088/0022-3727/47/5/05520 4

41. Raud J, Jõgi I, Laan M, Laast M (2013) Temporal and spectral characteristics of atmospheric pressure argon plasma jet. EPJ Appl Phys 61:2-7. https://doi.org/10.1051/epjap/2013120432

42. Jõgi I, Talviste R, Raud J et al (2014) The influence of the tube diameter on the properties of an atmospheric pressure $\mathrm{He}$ micro-plasma jet. J Phys D Appl Phys 47:415202. https://doi. org/10.1088/0022-3727/47/41/415202

43. Talviste R, Jõgi I, Raud J, Paris P (2016) Development of Ionization waves in an atmospheric-pressure micro-plasma jet. Contrib to Plasma Phys 56:134-145. https://doi.org/10.1002/ ctpp. 201500050

44. Jõgi I, Talviste R, Raud S (2020) Comparison of two cold atmospheric pressure plasma jet configurations in argon. Contrib to Plasma Phys 60:201900127. https://doi.org/10.1002/ctpp.20190 0127
45. Talviste R, Jõgi I, Raud J, Paris P (2016) The effect of dielectric tube diameter on the propagation velocity of ionization waves in a He atmospheric-pressure micro-plasma jet. J Phys D Appl Phys 49:195201. https://doi.org/10.1088/00223727/49/19/195201

46. Xiong R, Xiong Q, Nikiforov AY et al (2012) Influence of helium mole fraction distribution on the properties of cold atmospheric pressure helium plasma jets. J Appl Phys 112:1-9. https://doi. org/10.1063/1.4746700

47. Fantz U (2006) Basics of plasma spectroscopy. Plasma Sources Sci Technol 15:137-147. https://doi.org/10.1088/0963-0252/15/4/ S01

48. Jánský J, Bourdon A (2011) Simulation of helium discharge ignition and dynamics in thin tubes at atmospheric pressure. Appl Phys Lett 99:3-6. https://doi.org/10.1063/1.3655199

49. Sretenović GB, Krstić IB, Kovačević VV et al (2014) Spatio-temporally resolved electric field measurements in helium plasma jet. J Phys D Appl Phys 47:355201. https://doi.org/10.1088/00223727/47/10/102001

50. Lu Y, Wu S, Cheng W, Lu X (2017) Electric field measurements in an atmospheric-pressure microplasma jet using stark polarization emission spectroscopy of helium atom. Eur Phys J Spec Top 226:2979-2989. https://doi.org/10.1140/epjst/e2016-60334-7

Publisher's Note Springer Nature remains neutral with regard to jurisdictional claims in published maps and institutional affiliations. 